\title{
RBEP
}

\section{A formação de professores para Educação de Jovens e Adultos (EJA): as pesquisas na Argentina e no Brasil}

Marcos Villela Pereira

Mónica de la Fare

\section{Resumo}

Resulta de uma parceria entre pesquisadores argentinos e brasileiros, por meio da qual vem se realizando uma pesquisa conjunta focalizada na análise da produção de conhecimentos em temas da Educação de Jovens e Adultos (EJA) nos dois países. Neste trabalho, apresentamos resultados com foco em estudos e pesquisas sobre formação de professores para a EJA na Argentina e no Brasil. Para sua realização, partimos de um estudo realizado na Argentina sobre a história da pesquisa nos temas da EJA nesse país e de estados do conhecimento publicados no Brasil. Como primeiro resultado, foi possível identificar um panorama paradoxal: por um lado, uma relativa escassez de trabalhos oriundos de pesquisas diretamente relacionadas com a formação de professores para a EJA, numa área de estudos com agendas fortemente atravessadas por essa modalidade como objeto do discurso da política educacional dos organismos nacionais e internacionais; por outro, uma história bastante longa de estudos e pesquisas sobre a formação de professores no campo da educação. A partir dessa análise, propomos uma linha de reflexão que permita pensar outros pontos de vista nas pesquisas associadas à formação de professores para a EJA.

Palavras-chave: formação de professores; EJA; Argentina; Brasil. 


\section{Abstract \\ Teacher education for Youth and Adult Education: researches in Argentina and Brazil}

The present work resulted from a partnership of researchers from Brazil and Argentina focused on the analysis of knowledge production concerning Youth and Adult Education in these countries. This work presents the results of studies and research about teacher education for Youth and Adult Education in Argentina and Brazil. The starting point was an Argentinean study aimed at the history of the research in this field and works published in Brazil. As a first result it identified a paradoxal overview: on one hand a relative scarcity of academic works focused on teacher education for Youth and Adult Education, in an area of study with a strong concern about Youth and Adult Education as an object present in the national and international educational policy discourse; on the other hand a large number of works focused on teacher education as a whole. This work proposes a reflection that enables other points of view associated to teacher education for Youth and Adult Education.

Keywords: teacher education; Youth and Adult Education; Argentina, Brazil.

Este artigo é resultado de uma parceria entre pesquisadores argentinos e brasileiros, a partir de atividades desenvolvidas no marco de um convênio de cooperação binacional. ${ }^{1}$ A primeira etapa priorizou o intercâmbio de professores e estudantes dos programas de pós-graduação envolvidos, e num segundo período foi possível avançar na realização de uma pesquisa conjunta com foco na problematização da produção de conhecimento em torno de temas da Educação de Jovens e Adultos (EJA) na Argentina e no Brasil.

No início dessa parceria, levando em consideração resultados de investigações que realizamos previamente, optamos por focalizar nossa análise na produção de conhecimentos sobre formação de professores para a EJA nos dois países. Para isso, realizamos um estudo da situação das pesquisas nesse tema na Argentina e no Brasil no campo educacional; no caso da Argentina, tendo como antecedente uma pesquisa realizada sobre as principais discussões, ideias e debates na EJA, complementado por uma análise da produção de pesquisas publicadas a partir da década de 90, e, no caso do Brasil, a partir do estudo das publicações de outros pesquisadores sobre estados do conhecimento em temas da EJA, focalizadas nas teses de doutorado e dissertações de mestrado produzidas nas últimas décadas. 
O trabalho conjunto que apresentamos constitui um ponto de partida e inclui resultados parciais da pesquisa iniciada. A primeira parte apresenta uma síntese da análise das pesquisas relacionadas ao tema da formação de professores da EJA no campo de estudos em educação, na Argentina e no Brasil, destacando algumas de suas características. A partir dessa análise, na segunda parte são introduzidas reflexões, tentando contribuir com a construção de pontos de vista a respeito da formação de professores para a EJA nos dois países.

\section{A formação de professores para a EJA como tema de pesquisa o campo educacional}

Na multiplicidade de temas de pesquisa reconhecidos no campo dos estudos em educação, a formação de professores é vista como "um clássico". Nesse sentido, é possível afirmar que, desde que se começou a sistematizar a prática pedagógica, o tema da formação está em pauta. Se quisermos, podemos identificar marcos históricos significativos que vão desde os preceitos socráticos, presentes nos Diálogos deixados por Platão, passando pela Didática Magna, de Comenius, até os mais recentes documentos e propostas publicadas pela Organização das Nações Unidas para a Educação, a Ciência e a Cultura (Unesco) ou pelos inumeráveis centros de estudo e pesquisa espalhados pelo mundo.

Por outra parte, em relação à EJA, embora o tema da formação de professores não apresente a mesma acumulação reconhecida para esses estudos no campo educacional em geral, é possível identificar que também integrou a pauta das primeiras publicações regionais especializadas em EJA. No primeiro número da Revista Interamericana de Educación de Adultos (Rieda), espaço fundador de divulgação dos trabalhos especializados em EJA na América Latina (publicada a partir de 1978), ${ }^{2}$ destaca-se um artigo relacionado à formação docente para a educação de adultos (Velásquez, 1978). Nesse trabalho, apresenta-se uma definição da EJA focalizada nas funções e finalidades dessa modalidade, questão baseada - como se depreende da citação do artigo - na Declaração de Nairobi (Unesco, 1976), documento de recomendações para o desenvolvimento da educação de adultos aprovadas pela Conferência Geral desse organismo na sua $19^{\mathrm{a}}$ Reunião. $^{3}$

A partir dessas ideias, Velásquez (1978) - em sintonia com ideias desenvolvimentistas que ganharam impulso na década de 60 - formulava quatro interrogações para o planejamento e a execução de programas de educação de adultos referentes aos "recursos humanos" (assim denomina os educadores), às instituições, aos eixos teóricos de um programa de formação e às características dos métodos e procedimentos nesses processos de formação. Da leitura do artigo, depreende-se que as respostas a essas perguntas levam à definição de um perfil do educador de adultos como recurso humano desejável. A partir dessa noção, o autor apresenta os requisitos que deveriam cumprir as instituições de formação de professores da EJA e os conteúdos a serem contemplados.

\footnotetext{
2 Os primeiros seis números foram publicados no Chile pelo Departamento de Educação da Organização dos Estados Americanos (OEA). Posteriormente e até a atualidade é publicada pelo Centro de Cooperación Regional para la Educación de Adultos en América Latina y el Caribe (Crefal).

${ }^{3}$ Por outra parte, atualmente a definição da EJA adotada pelas Conferências Internacionais de Educação de Adultos (Confinteas) emerge das primeiras formulações emanadas desse documento, reformuladas na V Confintea, apresentadas na Declaração de Hamburgo (Unesco, 1997), e, posteriormente, reafirmadas no documento final da VI Confintea (Unesco, 2009) realizada em Belém, Brasil.
} 
Esse breve exemplo permite identificar, no tema da formação de professores da EJA, uma das características que emergem da história da produção de conhecimentos especializados nessa modalidade nos países que são objeto deste trabalho. Nessa linha de análise, por exemplo, é possível reconhecer - no fim da década de 50 e no início da década de 60 - a centralidade do analfabetismo como tema de pesquisas e estudos, entendido como problemática a ser "combatida" e como obstáculo para o desenvolvimento dos países considerados na época "subdesenvolvidos" ou em "vias de desenvolvimento". Nesse contexto, o tema do analfabetismo (e suas possibilidades de "mensuração" por meio da estatística) se instalou nas agendas de pesquisa e também nas ações de política educativa da região mediante a realização de campanhas nacionais, ${ }^{4}$ no auge do ideário desenvolvimentista.

Essa característica, que não é exclusiva da produção em temas da EJA no campo educacional, exige na área da pesquisa tensionar a reflexividade, considerada inerente aos processos investigativos, e demanda distinguir, especialmente por parte dos pesquisadores, certas indistinções que fazem referência à EJA como "objeto do discurso da política educacional" dos organismos nacionais e internacionais e como "objeto de pesquisa", ou seja, como campo de práticas educacionais a partir das quais podem ser construídos problemas de pesquisa. Embora indissociáveis em qualquer estudo sócio-histórico que permita reconhecer a configuração das investigações em temas da EJA no campo educacional, esses atravessamentos necessitam ser interrogados na área da pesquisa.

Por outra parte, em sintonia com a linha de análise que sustentamos e que assinala como característica a baixa autonomia dos estudos associados à EJA, também se destaca a sensibilidade apresentada por essas produções em relação aos aspectos intelectuais da região - por exemplo, na abertura democrática experimentada por distintos países da América Latina nos meados da década de 80. Nesses anos, os temas da democratização, da participação e também da Educação Popular estiveram no centro das produções da EJA; como exemplo, destaca-se a publicação da revista do Consejo de Educación de Adultos en América Latina (Ceaal), com o título de La Piragua: Revista Latinoamericana de Educación y Política. O primeiro número dessa publicação, editado no Chile em 1989, apresentou como tema Educação Popular e Democracia e contou com a participação de destacados autores da América Latina, entre outros, Francisco Vío Grossi, Diego Palma e Orlando Fals Borda. Também no contexto desses anos, verifica-se maior vigência da utilização de abordagens participativas nas pesquisas (pesquisa-ação, pesquisa participante) que parecem ter declinado, pelo menos na frequência de seu uso. Conjecturamos que a partir dos processos de avanço da institucionalização das atividades

${ }^{4}$ Na Argentina, a primeira campanha nacional de alfabetização data dessa década; no Brasil e em outros países da América Latina, foram iniciadas em décadas anteriores. investigativas nas últimas décadas, especialmente nas universidades, isso aparece por efeito.

Além das características já apresentadas, o panorama das pesquisas em EJA nos dois países escolhidos para a realização deste estudo permite identificar, no Brasil, estados do conhecimento realizados em relação aos 
temas da EJA que antecedem ao único estudo identificado na produção argentina. ${ }^{5} \mathrm{O}$ trabalho coordenado por Haddad (2002) retrata o panorama das pesquisas desenvolvidas em teses de doutorado e dissertações de mestrado em temas da EJA, por meio do estudo de trabalhos defendidos no período 1986-1998. A partir desse universo de trabalhos, o primeiro tema (analisado por Maria Margarida Machado) refere-se aos que abordavam assuntos associados à formação do professor. Trata-se de 32 pesquisas (4 teses de doutorado e 28 dissertações de mestrado), de um total de 183 trabalhos estudados, organizados para essa análise em dois subtemas: relações professor/aluno e visões sobre a EJA (uma tese e 11 dissertações) e as práticas de formação do professor, 9 dissertações referentes à prática pedagógica e 11 pesquisas (3 teses e 8 dissertações) que focalizam a formação de professores da EJA (Machado, 2002).

Outro estudo evidenciado nas dissertações e teses em temas da EJA realizadas no período 1987-2006 (Carvalho, 2009), tendo como fonte o banco de dados da Coordenação de Aperfeiçoamento de Pessoal de Nível Superior (Capes), assinala que foram defendidas 513 dissertações de mestrado e 77 teses de doutorado em temas dessa modalidade, confirmando a tendência de predomínio de dissertações de mestrado já identificada no trabalho coordenado por Haddad (2002). Esse estudo destaca que somente após 1996 se verifica um aumento significativo desses trabalhos, os quais experimentaram um maior incremento no início dos anos 2000. A autora associa essa característica à normatização da Lei de Diretrizes e Bases da Educação (LDB) no que diz respeito à EJA, pelo Conselho Nacional de Educação, a partir do ano 2000 - com a promulgação do Parecer CNE/ CEB no 11/2000 sobre as Diretrizes Curriculares Nacionais para EJA e da Resolução do CNE/CEB n 1, de 5 de julho de 2000, que estabelece essas diretrizes (Carvalho, 2009, p. 118-119). Por outra parte, destaca-se neste trabalho que, do total de teses de doutorado e dissertações de mestrado, apenas 17\% referem-se a currículo, formação de professores e prática pedagógica.

Junto a esses trabalhos, a pesquisa realizada por Soares (2006) retrata o panorama da formação de professores para a EJA no Brasil, revelando a escassez de discussões mais aprofundadas na área. O autor constata que, mesmo com a crescente visibilidade da EJA nos últimos anos como instância de práticas e como campo de estudos e pesquisas, não é possível reconhecer ainda uma demanda efetiva pela formação especializada de educadores (Soares, 2006, p. 15).

No caso específico da Associação Nacional de Pós-Graduação e Pesquisa em Educação (Anped), principal entidade da área, em 1998 foi criado o Grupo de Trabalho (GT) sobre Educação de Jovens e Adultos, originário da confluência dos GTs Movimentos Sociais e Educação Popular. Nesses mais de dez anos de existência, são apenas 18 trabalhos (em um conjunto de 150) que tematizam a formação de educadores.

Na Argentina, é possível reconhecer ensaios, artigos de jornais e documentos que abordam questões associadas às Escolas para Adultos a partir da segunda metade do século 19 e nos princípios do século $20,{ }^{6}$ no
${ }^{5}$ No caso do Brasil, destaca-se um estudo concluído em 1988, mencionado no estado do conhecimento referido ao período 1986-1988 (Haddad, 2002); no caso da Argentina, estamos fazendo referência ao estado do conhecimento elaborado por um dos autores deste texto.

${ }^{6}$ Os primeiros escritos publicados sobre escolas para adultos desta época são de autoria de Domingo Faustino Sarmiento, identificados em seu livro $\mathrm{De}$ la Educación Popular de 1849 e em artigos de jornal escritos nesses anos. 
contexto do modelo da Instrução Pública da época (De La Fare, 2010a). Além dessas primeiras produções, a pesquisa em temas associados à EJA - como a conhecemos hoje - emerge na década de 60 do século 20, no contexto das ideias e ações governamentais desenvolvimentistas. Dita emergência se vincula principalmente a processos sociopolíticos mais amplos que não podem ser lidos como próprios da EJA, porém associados a movimentos e transformações políticas mais abrangentes. Como já foi assinalado em outra oportunidade, a identificação desse período de quase 50 anos não pode ser pensada como uma continuidade, uma vez que as ditaduras de 1966 e, especialmente, a de 1976, com sua política de extermínio, provocaram a interrupção de boa parte das experiências de Educação Popular desenvolvidas a partir da militância política e social e da extensão universitária, iniciadas a partir do fim da década de 50. Também foram interrompidas as atividades de pesquisa e de produção de conhecimento em muitas outras áreas, incluindo as do campo educacional e, de modo geral, nas Humanidades e nas Ciências Sociais, posteriormente retomadas a partir da abertura democrática de 1983 (De La Fare, 2010b).

A partir dessas emergências e interrupções da produção de conhecimentos nos temas da EJA, é possível reconhecer a realização de algumas pesquisas na década de 80 e um incremento e diversificação das produções na década de 90 (especialmente nos anos 2000), porém as pesquisas em EJA continuam sendo escassas. Nesse panorama, os estudos sobre formação de professores em geral e sobre os docentes dessa modalidade são quase inexistentes. As investigações históricas e sociopolíticas que predominam no pequeno universo dessas pesquisas centraram-se nas ações políticas e nos estudantes da EJA como sujeitos de processos políticos e educativos, mas não têm contemplado adequadamente os professores e seus espaços de formação específica.

Esse breve panorama permite identificar, nos dois países, características comuns aos estudos sobre formação de professores da EJA. Na Argentina e no Brasil, as pesquisas em temas da EJA se incrementaram a partir das últimas duas décadas, embora seja possível reconhecer uma maior produtividade de teses de doutorado e dissertações de mestrado no Brasil, aspecto que deriva das características da pós-graduação nesse país, que apresenta diferenças importantes da Argentina - aspecto que merece uma análise mais demorada que excede os limites deste trabalho. Nesse contexto de incremento do número de pesquisas, as referidas aos professores da EJA e sua formação, em geral, não predominaram.

No Brasil, até a edição das Diretrizes Curriculares Nacionais para os Cursos de Pedagogia, ainda era possível encontrarmos cursos de graduação com a habilitação em EJA disponível. De 2006 para cá, desaparecida a prerrogativa de oferta dessa natureza, o máximo que encontramos é alguma disciplina específica ofertada ao longo dos currículos ou como modalidade de estágio, ou em nível de pós-graduação (especialmente lato sensu). Em termos de pós-graduação stricto sensu, vale o destaque para a Universidade Federal da Paraíba (UFPB) e para a Universidade Federal de Minas Gerais (UFMG), que oferecem a oportunidade de cursar o mestrado 
ou o doutorado em linhas de pesquisa mais dirigidas para a EJA (linha de pesquisa em Educação Popular, na UFPB, e Movimentos Sociais, Educação e Cultura, na UFMG).

$\mathrm{Na}$ Argentina, ainda sem existir pós-graduação stricto sensu especializada em EJA, também são escassos os trabalhos que abordam esse tema nos mestrados e doutorados em educação credenciados até o ano de 2009. Embora não existam estudos que especifiquem em detalhe os espaços de formação docente especializada, é possível assinalar, a partir de um levantamento inicial de dados empíricos, que esses espaços se desenvolvem no nível da graduação - uma universidade nacional (Universidad Nacional de Luján) tem um curso denominado "Profesorado en Enseñanza Media de Adultos"; nas demais, verifica-se apenas algumas orientações de cursos de professorado e licenciatura em Ciências da Educação. Também se desenvolvem cursos de formação em serviço para professores e se constata a existência de alguns poucos cursos de nível superior terciário para docentes, denominados "postítulos", com pouca continuidade em sua implementação.

Em síntese, o breve panorama apresentado assinala que nos dois países as pesquisas sobre formação de professores para a EJA são escassas, mesmo tendo aumentado a visibilidade dos estudos nessa modalidade em geral. Com relação aos contextos de produção reflexiva do tema, uma diferença relevante é, no caso do Brasil, a realização de seminários nacionais sobre formação de educadores de jovens e adultos, que tendem a institucionalizar espaços específicos e especializados de debate e produção, fato que até agora não acontece na Argentina.

Ainda estamos em processo de construção de algumas chaves interpretativas que nos permitam compreender melhor esses processos. Uma hipótese em relação ao caso argentino associa o incremento e a diversificação de pesquisas publicadas em temas da EJA a um aumento geral das publicações no campo de estudos em educação - em parte, produto das políticas de avaliação das universidades, incluindo instituições e pesquisadores, que estabelecem parâmetros de mensuração da produtividade e têm produzido significativo aumento do número de revistas especializadas em temas de educação e de outros campos do conhecimento afins.

Por outra parte, ao olhar os estudos do campo educacional, é possível identificar nos dois países um considerável acúmulo de produções que problematizaram a formação de professores em geral (e não especificamente no âmbito da EJA): numerosos trabalhos elaborados a partir das mais diferentes matrizes de pensamento, das mais distintas prescrições e dos mais diversos modelos de formação, de modo geral. Nesse sentido, destacamos que as pesquisas em formação de docentes para a EJA se desenvolvem no campo de estudos em educação, constituindo o tema de formação de professores, como já foi assinalado, um assunto clássico com uma considerável acumulação de produções: ensaios, pesquisas, prescrições, orientações para a ação, etc.

Nesse desenvolvimento e acumulação de produções, as pesquisas sobre formação de professores do campo educacional mais amplo muitas 
vezes tiveram por objetivo pensar como deve se dar o processo de formação desses sujeitos que vão capitanear a experiência de formação de outros sujeitos: como devem ser, o que devem saber, como devem proceder esses sujeitos que vão implementar situações de ensino e aprendizagem? É possível reconhecer que já perseguimos nas produções do campo educacional a definição de perfis, identidades, papéis, funções, características, atributos, fundamentos, competências, significados, modelos, receitas, programas, um sem-número de modos mais ou menos exemplares de pensar a formação docente. No caso da formação de professores para a EJA, entretanto, esse material é escasso: o que encontramos, às vezes, são propostas de deslocamento ou transposição de procedimentos, prescrições, metodologias e currículos de outros níveis e modalidades para a formação de educadores de jovens e adultos.

Das ideias apresentadas nesta primeira parte do trabalho, é possível distinguir que temos em mãos um panorama um tanto paradoxal: por um lado, uma relativa escassez de trabalhos oriundos de pesquisas diretamente relacionadas à formação de educadores para a Educação de Jovens e Adultos, numa área temática emergente e com agendas de pesquisa fortemente atravessadas pela EJA como objeto do discurso da política educacional dos organismos nacionais e internacionais; por outro lado, uma história bastante longa de preocupação com a formação de educadores e de produções sobre esse tema no campo educacional. Esse estado da produção convida a reconhecer a possibilidade de interrogar os pontos de vista a partir dos quais muitas produções foram construídas e propor outros, não como uma saída, uma receita ou um ponto de chegada, mas para potenciar certos deslocamentos de nossos focos habituais de atenção.

Podemos dizer que, em certa medida, a análise proposta advém menos das agendas de política educativa de diferentes organismos do que de algumas questões inerentes à pesquisa no campo educacional, nesse caso focalizada no tema de formação de professores para a EJA, atravessado pela revisão das produções referidas à formação de professores em geral.

\section{A construção de outros pontos de vista na pesquisa sobre formação de professores na EJA}

Para efeitos da análise, nesta segunda parte do trabalho, tomamos como subsídio um postulado foucaultiano acerca da pesquisa históricofilosófica. Em seu curso "El gobierno de sí y de los otros", Foucault (2009, p. 18-19) propõe a história do pensamento como uma possibilidade de análise que se aloja entre a história das mentalidades (uma análise que vai dos comportamentos efetivos às expressões que os acompanham) e a das representações (uma análise que articula as ideologias subjacentes às práticas em articulação com o sistema de referência hegemônico de valores representativos de um certo sistema de representações). A esse 
exercício, ele caracteriza como uma articulação de três eixos ou três focos de experiência: primeiro, as formas de um saber possível; segundo, as matrizes normativas de comportamento para os indivíduos; terceiro, modos de existência virtuais para sujeitos possíveis (Foucault, 2009, p. 19).

Num trabalho anterior (Pereira, 2010), foram tomados como questão os três eixos referidos nessa análise para pensar a formação de professores como "objeto" de pesquisa, a partir de alguns exemplos da história recente dos estudos produzidos sobre o tema da formação de professores no campo educacional. Nessa oportunidade, foi realizado um exercício analítico por meio da construção de um breve panorama sobre a emergência de algumas noções, algumas teorizações sobre a formação de professores. Nesta apresentação nos limitaremos a realizar uma síntese dessas ideias já desenvolvidas.

O primeiro foco, em certa medida, leva-nos a reconhecer e revisar a história da pesquisa sobre a formação de professores, como vasto inventário de conhecimentos possíveis acerca do seu percurso formativo. Nesse sentido, por exemplo, reconhecemos no trabalho de Cayetano De Lella (2005) quatro modelos formativos: prático-artesanal (a professoralidade concebida como um ofício que se aprende numa oficina, taller, workshop - forma de transmissão bastante tradicional que se consolida pelos processos de socialização e adaptação geracional); academicista (centrado no domínio da disciplina que o professor ensina e nas habilidades didáticas para a transmissão desse saber); técnico-eficientista (como foco na tentativa de um ensino tecnificado pela articulação entre economia de esforços e uma eficiência de processos e produtos); e hermenêuticoreflexivo (concebe o ensino como atividade complexa, sobredeterminada pelo contexto macrossocial, carregada de conflitos de valor que requerem opções éticas e políticas).

Numa outra direção, podemos acompanhar os estudos das últimas décadas sobre os saberes e a formação docente de Tardif e Lessard (1999) e Tardif (2008). Este autor tem postulado a ideia de que um programa de formação para o ensino é uma construção social produto de crenças, convicções, valores, debates e escolhas realizadas no confronto entre diversos grupos de sujeitos socioeducativos. Esse plano deve ser entendido no jogo de equilíbrio entre tradições, um meio sociocultural geralmente instável e diferentes visões de futuro e necessidades profissionais (Tardif, 2008, p. 20). Na medida em que trabalhar remete a dominar progressivamente os saberes necessários à realização do trabalho, é necessário que os trabalhadores desenvolvam, progressivamente, saberes oriundos do próprio processo de trabalho e nele baseados. Segundo essa perspectiva, os saberes dos professores parecem ser plurais e heterogêneos e trazem à tona, no próprio processo de trabalho, conhecimentos e manifestações do saber-fazer e do saber-ser diversificados e provenientes de fontes variadas.

Uma outra perspectiva provém da transferência, do mundo do trabalho para o campo da educação, do conceito de competência. Esse movimento tem sua gênese em pesquisas realizadas no começo da segunda 
metade do século 20, principalmente nos Estados Unidos, cujos resultados revelaram que os trabalhadores com melhor desempenho tinham, além dos conhecimentos específicos, habilidades e destrezas relacionadas com certas crenças, valores, percepções e intuições, que asseguravam seu melhor desempenho; a essas habilidades e destrezas se atribuiu o termo "competências". Durante a década de 90, o desenvolvimento da psicologia cognitiva e das neurociências se alinhou com a necessidade de levar o sujeito a aplicar o conteúdo de suas aprendizagens em situações concretas, novas e complexas, aprofundando na associação da noção de competência à capacidade subjetiva de transformar informação em conhecimento. A noção de competência foi definida no Relatório Delors da Unesco como conjunto de comportamentos socioafetivos e habilidades cognitivas, psicológicas, sensoriais e motoras que permitem levar a cabo adequadamente um desempenho, uma função, uma atividade ou tarefa (Delors, 1998). Nesse relatório, estabeleceu-se a necessidade de que os governos se comprometessem a desenhar seus programas educativos baseados em competências.

Estas três matrizes de concepção de saberes docentes nos permitem trabalhar o primeiro foco da análise foucaultiana, relativo à identificação de diferentes formas possíveis de conceber as verdades e certezas com as que trabalhamos. Trata-se de substituir a história pura e simples de conhecimento propriamente dito pela análise histórica das formas e mecanismos que fazem com que um certo conhecimento seja tido como verdadeiro numa determinada circunstancia, época ou conjuntura (Foucault, 2009, p. 21).

Em relação ao segundo foco apontado por Foucault, referente à análise das matrizes normativas de comportamento para os indivíduos, podemos dizer que a história da pesquisa sobre a formação de professores representa um minucioso exercício de investigação de modelos de dominação e, consequentemente, um inventário de conhecimentos possíveis sobre as principais matrizes reguladoras de comportamentos. Ao sobrevoar a história recente da pesquisa sobre formação de professores, é possível verificar as transformações (às vezes sutis, às vezes drásticas) no modo como se concebe o sujeito, que ficam evidentes nesses postulados emergentes nos diferentes campos que constituem os arranjos disciplinares aí implicados.

Tomando em questão o terceiro foco de experiência apontado por Foucault - análise dos modos de existência virtuais para sujeitos possíveis -, podemos dizer que a história recente da pesquisa sobre a formação de professores constitui um inventário amplo e infinito de modos possíveis de ser professor. Cada pesquisa, programa, currículo ou preceito oferece uma possibilidade de entender o ato de ensinar; portanto, tomando-se cada um como uma razão plausível, eles representam um modo possível de experimentar a prática docente. Para além de descrever ou analisar cada forma possível ou existente de prática pedagógica, trata-se de investigar a pragmática, ou melhor, a estética da professoralidade - pensar diferentes formas de ser professor por meio da análise dos procedimentos 
e técnicas de relação de si consigo mesmo (como cada um se pensa, se vê, se diz, se torna professor) (Pereira, 1996).

A pesquisa sobre a formação de professores, sob esse foco, constitui um exercício analítico-interpretativo (por que não dizer hermenêutico) que opera no marco da tradição da crítica como a ideia de que as coisas poderiam ser de outra maneira além da que está sendo, a crítica como a abertura consciente para a posição do outro, como ancorada em uma razão possível, como uma atitude de indulgência ante a existência de tantas concepções, ideias e razões simultâneas e possíveis quantos são os sujeitos implicados em um acontecimento (Hermann, 2003).

A pesquisa sobre a formação representa investigar as possibilidades de constituir-se professor de jovens e adultos no próprio ato de tornar-se professor. Que dispositivos, técnicas, artifícios, procedimentos, expedientes e truques um professor, no âmbito da prática, coloca em funcionamento, lança mão, opera, arranja, articula, tendo em vista a necessidade de permanente tomada de decisão ante as incontáveis vicissitudes da realidade da sua turma, do seu grupo, da sua escola, da sua comunidade?

Não existe a intenção, nesse caso, de pretender-se alcançar a resposta ou a saída. A atitude crítica representa um efeito do exercício do sujeito que pondera não com vista a fazer uma escolha pela alternativa certa ou verdadeira, mas com vista a compreender-se implicado naquilo que o constitui, com vista a entender-se em relação ao mundo e ao outro envolvidos no acontecimento presente.

\section{Referências bibliográficas}

BRASIL. Conselho Nacional de Educação (CNE). Câmara de Educação Básica (CEB). Parecer CNE/CEB no 11/2000, de 10 de maio de 2000. Dispõe sobre as Diretrizes Curriculares Nacionais para a Educação de Jovens e Adultos. Disponível em: < http://portal.mec.gov.br/index. php?option $=$ com_content\&view $=$ article\&id $=13252 \% 3$ Aparecer-ceb$2000 \&$ catid $=323 \% 3$ Aorgaos-vinculados $\&$ Itemid $=866>$.

Resolução CNE/CEB no 1, de 5 de julho de 2000. Estabelece as Diretrizes Curriculares Nacionais para a Educação de Jovens e Adultos. Disponível em: < portal.mec.gov.br/cne/arquivos/pdf/CEB012000.pdf> .

CARVALHO, Roseli Vaz. O estado da arte das pesquisas em Educação de Jovens e Adultos na CAPES: período de 1987-2006. Cadernos de Pesquisa Pensamento Educacional, Curitiba, v. 4, n. 8, p. 117-130, jul./ dez. 2009. Disponível em: <http://www.utp.br/revistaseletronicas.asp>.

DE LA FARE, Mónica. La Educación de Jóvenes y Adultos en Argentina: principales ideas, discusiones y estado actual del conocimiento: aportes 
para una reconstrucción histórica. Buenos Aires: Área de Investigación y Evaluación de Programas, DiNIECE, Ministerio de Educación, 2010a.

DE LA FARE, Mónica. La investigación en torno a los temas de la Educación de Jóvenes y Adultos en Argentina en las últimas décadas. Trabalho apresentado no $4^{\circ}$ Painel (A formação do educador de EJA em países latino-americanos) do III Seminário Nacional de Formação de Educadores de EJA, Porto Alegre, 2010b.

DE LELLA, Cayetano. Formación docente: el modelo hermenéutico-reflexivo y la práctica profesional. Decisio: saberes para la acción en educación de adultos, México, n. 5, otoño 2005. Disponível em: < http://tariacuri.crefal.edu.mx/decisio/d5/sab3-1. php?revista $=5 \&$ saber $=3>$.

DELORS, Jacques. Educação: um tesouro a descobrir. São Paulo: Cortez, Unesco, MEC, 1998.

FOUCAULT, Michel. El gobierno de si y de los otros: curso en el Collège de France, 1982- 1983. Buenos Aires: Fondo de Cultura Económica, 2009 .

HADDAD, Sérgio (Coord.). Educação de jovens e adultos no Brasil (1986-1988). Brasília: MEC/Inep, Comped, 2002.

HERMANN, Nadja. Hermenêutica e educação. Rio de Janeiro: DP \& A, 2003

MACHADO, Margarida. A prática e a formação de professores na EJA. In: HADDAD, Sérgio (Coord.). Educação de jovens e adultos no Brasil (1986-1988). Brasília: MEC/Inep, Comped, 2002.

PEREIRA, Marcos Villela. Crítica, estética e professoralização: um olhar para a pesquisa sobre formação de professores para EJA. Trabalho apresentado no $5^{\circ}$ Painel do III Seminário Nacional de Formação de Educadores de EJA, Porto Alegre, 2010.

PEREIRA, Marcos Villela. Estética da professoralidade: um estudo interdisciplinar sobre a subjetividade do professor. Tese (Doutorado em Supervisão e Currículo) - Pontifícia Universidade Católica de São Paulo (PUC-SP), 1996.

SOARES, Leôncio. O educador de jovens e adultos em formação. In: REUNIÃO ANUAL DA ANPEd, 29., 2006, Caxambu. [Anais....]. Trabalho apresentado no GT18 - Educação de Pessoas Jovens e Adultas. Caxambu, 2006. < http://www.anped.org.br/reunioes/29ra/ trabalhos/trabalho/GT18-2030--Int.pdf>. 
TARDIF, Maurice. Princípios para guiar a aplicação dos programas de formação inicial para o ensino In: ENCONTRO NACIONAL DE DIDÁTICA E PRÁTICA DE ENSINO (Endipe), 14., 2008, Porto Alegre. Anais: trajetórias e processos de ensinar e aprender: didática e formação de professores. Porto Alegre: EDIPUCRS, 2008. p. 17-46.

TARDIF, M.; LESSARD, C. Le travail enseignant au quotidien: contribution à l'étude du travail dans les métiers et les professions d'interactions humaines. Quebec: De Boeck, PUL, 1999.

TARDIF, Maurice; RAYMOND, Danielle. Saberes, tempo e aprendizagem do trabalho no magistério. Educação \& Sociedade, Campinas, v. 21, n. 73, p. 209-244, dez. 2000.

UNESCO. Aprovechar el poder y el potencial del aprendizaje y la educación de adultos para un futuro viable: Marco de Acción de Belém. Belém, 2009.

La educación de las personas adultas: la Declaración de Hamburgo, la agenda para el futuro. In: CONFERENCIA INTERNACIONAL DE EDUCACIÓN DE LAS PERSONAS ADULTAS, $5 .$, 1997, Hamburgo. Disponible en: < http://www.unesco.org/education/ uie/confintea/pdf/con5spa.pdf>.

Recomendación relativa al desarrollo de la educación de adultos. Nairobi, 1976

VELÁSQUEZ, Adalberto. La formación docente para la educación de adultos. Revista Interamericana de Educación de Adultos, Santiago de Chile, v. 1, n. 1, 1978.

Marcos Villela Pereira, doutor em Educação, é professor titular do Programa de Pós-Graduação em Educação da Pontifícia Universidade Católica do Rio Grande do Sul (PUC-RS).

marcos.villela@pucrs.br

Mónica de la Fare, doutora em Serviço Social, é professora do Programa de Doctorado en Ciencias de la Educación da Universidad Nacional de La Plata (UNLP) na Argentina e da Facultad Latinoamericana de Ciencias Sociales (Flacso).

monicadlf@gmail.com

Recebido em 20 de agosto de 2010.

Aprovado em 22 de dezembro de 2010. 